\title{
HISTÓRIAS QUE NÃO TÊM ERA UMA VEZ: ' AS (IN)CERTEZAS DA TRANSEXUALIDADE
}

\author{
Flavia do Bonsucesso Teixeira \\ Universidade Federal de Uberlândia
}

\begin{abstract}
Resumo: A partir de fragmentos das histórias de vida de pessoas (transexuais), tento explicitar a diversidade das suas vivências, experiências singulares, modos de dar sentido ao processo de ruptura das normas de gênero e da sexualidade. Analiso a insuficiência dos discursos médico e jurídico, ancorados numa verdade essencializada sobre o corpo sexuado, para capturar as possibilidades de experiências na transexualidade. Argumento que o potencial desestabilizador da transexualidade reside no distanciamento da máxima reducionista que considera os sujeitos como pessoas presas num corpo equivocado cuja inteligibilidade dependeria unicamente da cirurgia de transgenitalização.

Palavras-chave: transexualidade; gênero; sexualidade; transgenitalização.
\end{abstract}

Este artigo é composto de alguns excertos das entrevistas e das observações realizadas no período de 2004 a 2008 que integram a minha tese de doutorado. ${ }^{2}$ São relatos indicativos dos (re)arranjos, das negociações e dos conflitos que envolveram os diferentes sujeitos que romperam com a dualidade do sexo na construção subjetiva da transexualidade. As histórias de três pessoas (transexuais) ${ }^{3}$ foram tomadas como referência, analiso as experiências que contaram e foram escolhidas para compor o enunciado das suas vivências em contraposição e/ou reiterando os elementos dos discursos médico e jurídico.

Essas narrativas possibilitam mostrar como esses sujeitos construíram significados para suas vivências particulares, evidenciando o complexo rapport entre norma e indivíduo, subversão e conformismo, autonomia e assujeitamento. Permitem, também, captar a fluidez de suas posições e seus deslocamentos e identificar a especificidade de experiências que não se encontram fixas, cristalizadas em verdades definitivas.

Copyright $\odot 2012$ by Revista Estudos Feministas.

'Inspirado na música "Há uma história triste", composta por Niquinho e Othon Russo e interpretada por Elis Regina no álbum O bem do amor, de 1963.

${ }^{2}$ Defendida no programa de doutorado em Ciências Sociais da Unicamp, sob a orientação da prof.a Dr.a Adriana Piscitelli e coorientação da prof.a Dr.a Mariza Corrêa.

" É o reconhecimento da instabilidade do termo que assumo ao utilizar o termo "transexual" entre parênteses. 
Argumento que, no processo da construção de uma tecnologia de si, essas pessoas são conduzidas a um investimento identitário significativo - um novo nome, um corpo modificado - que dê sentido ao "não senso" de um corpo que parece ter se equivocado. Perceber as fraturas e os deslocamentos foi o posicionamento adotado aqui na tentativa de compreender a vida precária do gênero.

\section{... Qualquer curva de qualquer destino que desfaça o curso de qualquer certeza}

Carolina se constituiu na interlocutora principal da tese de doutorado que originou essas reflexões, não apenas pela disposição em compartilhar sua experiência, mas, sobretudo, pelas particularidades de sua história, marcada pelo trânsito entre os gêneros. Ao se inscrever no Programa de Transgenitalização, ${ }^{5}$ ela abriu brechas nos protocolos, pois, no passado, quando era reconhecida como homem, havia sido casada e tido uma filha, de menor idade quando iniciei a pesquisa. O ofício de militar, a realização da cirurgia após os 40 anos de idade, a autorização para alteração de nome e sexo, os novos documentos e a continuidade do processo, que não se encerraram aí, são os motivos que transformaram os seus relatos na urdidura para que outros fios fossem tramados compondo o texto que apresento a seguir.

Estava em Brasília e essa não seria a primeira vez em que eu acompanharia Carolina em suas consultas. Cheguei cedo à sua casa e, enquanto ela terminava de se arrumar, eu observava as medalhas na parede que testemunhavam uma carreira marcada pelas estratégias de sobrevivência. Foram 22 anos de serviço militar, trabalhando num universo eminentemente masculino, Carolina suportou uma vivência no gênero masculino por um período pouco comum para a maioria das mulheres (transexuais).

No percurso até o Hospital Regional da Asa Norte (HRAN), ela contou o ocorrido no dia anterior e as situações de constrangimentos a que fora submetida em função do nome de registro. Eu me lembrei do pedacinho de papel que muitas vezes a vi entregar para os/ as atendentes no qual estava escrito em letras cursivas, legível, mas em tom de súplica: "Por favor, me chame por Carolina". Ela parecia mendigar o que era direito. ${ }^{6}$

Não seria injustificada a sua insegurança, fundamentada em episódios anteriores de recorrentes constrangimentos. Entre os anexos de seu processo na Promotoria de Justiça, encontrei o relato sobre o episódio de discriminação ocorrido no Hospital Militar, no qual teve seu atendimento negado por um médico. Carolina relembra o momento em que o médico, indicando com um gesto de mão a saída do consultório, sem olhar para ela, determinou que fosse em casa, trocasse de roupas e assim seria atendida. O relato minucioso no processo, a cópia do relato que ela mantém em casa e o rubor de sua face quando relembra o episódio dizem do seu significado, que Carolina identifica como "cicatriz".

\footnotetext{
${ }^{4}$ Música "Qualquer“, composta por Arnaldo Antunes, Hélder Gonçalves e Manuela Azevedo e interpretada por Arnaldo Antunes no álbum Qualquer, de 2006.

${ }^{5}$ Coordenado pela Promotoria de Justiça Criminal da Defesa dos Usuários de Serviços de Saúde (Pró-Vida), do Ministério Público do Distrito Federal e Territórios, que possuía o objetivo de autorizar e viabilizar a cirurgia de transgenitalização.

6 Portaria MS n. 675, de 30 de março de 2006, que aprovou a Carta dos Direitos dos Usuários da Saúde e que estabeleceu no terceiro princípio a necessidade da existência, em todo documento de identificação do usuário, de um campo para registrar o nome pelo qual prefere ser chamado, independentemente do registro civil. Essa portaria foi revogada e substituída pela Portaria MS n. 1.820, de 13 de agosto de 2009, que, no quarto princípio, ratifica o direito previsto acima.
} 
Acredito, assim como Butler, ${ }^{7}$ que, se não fôssemos seres linguísticos, a linguagem não seria capaz de nos ferir ou causar danos. A autora alerta para o fato de utilizarmos metáforas de dores físicas para traduzir esse dano em algo inteligível, assim indicamos a dimensão materializada da relação entre corpo e linguagem.

El lenguaje preserva el cuerpo pero no de una manera literal trayéndolo a la vida o alimentándolo, más bien una cierta existencia social del cuerpo se hace posible gracias a su interpelación en términos de lenguaje. Para entender esto uno debe imaginarse una escena imposible en la que un cuerpo al que no le ha sido dada aún una definición social, un cuerpo que es, estrictamente hablando, inaccesible, se vuelve accesible en el momento en que nos dirigimos a él, con una llamada o una interpelación que no "descubre" el cuerpo, sino que lo constituye fundamentalmente. Podríamos pensar que para que se dirijan a uno, uno debe ser primero reconocible, pero en este caso la inversión althusseriana de Hegel parece apropiada: la llamada constituye a un ser dentro del circuito posible de reconocimiento y, en consecuencia, cuando esta constitución se da fuera de este circuito, ese ser se convierte en algo abyecto.

No relato de Carolina, o interlocutor a desloca do lugar de pessoa para um status de figuração, através do não reconhecimento de sua legitimidade. Embora no decorrer do texto do qual foi retirado esse excerto Judith Butler se contraponha ao conceito de interpelação desenvolvido por Althusser, nesse momento, a utilização se faz no sentido do compartilhamento de que é a chamada do outro que inauguraria o reconhecimento do sujeito. O insulto proferido pelo médico impediu Carolina de ocupar um lugar, através da recusa desse outro em interpelá-la.

Carolina era percebida em termos marcas de gênero, as quais faziam com que ela vivesse, cotidianamente, ao mesmo tempo, o não reconhecimento como pessoa e a dificuldade em passar despercebida. Era perceptível a atuação do hormônio masculino no corpo de Carolina, principalmente a proeminência de face com a angulação de testa e queixo. Ela relata que, durante a puberdade, a ausência do surgimento dos caracteres sexuais secundários preocupou os seus pais, que a levaram para a capital do estado a fim de ser examinada por especialistas. Referia, com ressentimento, ao tratamento imposto, principalmente das alterações físicas causadas pelo uso do hormônio. Essas mudanças externas, marcadas pelo surgimento de pelos e pela alteração de voz, potencializada pela raspagem das cordas vocais (sic), produziram o efeito de "colaborar" para que a natureza encontrasse seu caminho estabelecido a partir do sexo de nascimento. ${ }^{8}$

No seu caso, somado à aparência, à pouca desenvoltura ao andar sobre os saltos, a uma falta de harmonia no conjunto dos gestos, havia um "jeito de corpo" desejado que os anos de farda não the permitiram incorporar. ${ }^{9}$

\footnotetext{
7 Judith BUTLER, 2004, p. 21.

${ }^{8}$ Essa experiência não se constitui numa situação isolada. Tatiana Lionço $(2006$, p. 105) refere-se a casos em que dois dos sujeitos por ela entrevistados foram submetidos, na adolescência, a tratamentos endocrinológicos por seus corpos (e performances) não corresponderem às expectativas criadas a partir da genitália existente. O aspecto comum no relato das entrevistadas é a administração de "hormônios masculinos" como tratamento para um comportamento interpretado como feminino e, ainda, as pequenas ou ausentes demonstrações de masculinidades. Destaco os impactos das teorias que buscavam uma origem biológica para a homossexualidade, mais precisamente, a teoria da influência dos hormônios na orientação sexual adulta, cuja base explicativa estaria ancorada na insuficiência hormonal (testosterona). Tais teorias parecem ter influenciado na prescrição de terapêutica também das entrevistadas.

${ }^{9}$ A noção de incorporação que Juliana Jayme utiliza na sua pesquisa pareceu-me sugestiva para somar ao que Judith Butler (2001) chamaria de repetição estilizada de atos. A pesquisadora denomina de incorporação o aprendizado feito pelo corpo e nele observável. No seu trabalho, ela estabelece a diferença do uso de incorporação e adota a perspectiva sugerida por Eduardo Viveiros de Castro (Juliana Gonzaga JAYME, 1999, p. 9-10).
} 
No Hospital Militar, logo no portão da entrada, os olhares eram apenas indicadores dos constrangimentos seguintes. Nosso objetivo era a marcação de exames. Mesmo assim, percorremos cada corredor de consultórios. Paramos em frente à porta identificada como atendimento psicológico. Esse foi o local, no hospital, por onde ela iniciou sua busca pela modificação de sua condição:

Depois dos hormônios masculinos, por causa das mudanças físicas, a parte emocional também ficou abalada. Eu nunca deixei de ser mulher internamente, mas deixei a vida para viver o papel masculino. Eu acho que da forma como fiquei com o engrossamento da voz, a estrutura muscular, o desenvolvimento da genitália eu achava que não teria mais nenhuma chance de viver no feminino. Eu passei a viver o papel masculino diante da sociedade. Mas quando saiu a reportagem de Roberta Close falando sobre a cirurgia e dizendo que os hospitais brasileiros fariam a cirurgia eu voltei a pensar... mexeu comigo. Eu comecei a pensar se apesar da minha constituição física, apesar do prejuízo que eu tive, será que eu deveria continuar nessa minha vida masculina só para a sociedade ou se eu merecia uma segunda chance. Apesar de minha forma física.

Estar na sala de recepção do hospital era a repetição de um ritual - marcado pelos pressupostos dos saberes médicos e jurídicos - que se instaurou em 1997. Permanecemos sentadas na sala de espera pelo tempo que Carolina considerou necessário. Percebi a sua intenção de rever os colegas do tempo de atividade e ficou por ali na tentativa de que alguém parasse para conversar. Um homem aparentando a mesma idade que ela se aproximou; sem saber ao certo como se dirigir, evitou nomes e artigos, tornando a conversa quase monossilábica. O silêncio do interlocutor silencia Carolina. Compartilho a percepção de Butler ${ }^{11}$ no que se refere a considerar que o ato de fala é um ato corporal e se redobra no momento da fala, atribuindo a existência ao que se diz. Nesse sentido, o silêncio do militar pode ser entendido como um instrumento corporal que enuncia e realiza a inexistência de Carolina. A conversa foi breve, levantamo-nos e voltamos ao estacionamento do hospital.

Do carro, eu observava os alojamentos e a disposição dos prédios, então perguntei à Carolina os locais subterrâneos que ela utilizava como banheiro. Ela apontou então um local com uma escada, indicando um acesso subterrâneo. Durante o período em que trabalhou como militar, ela nunca dividiu o banheiro com seus colegas nem mesmo o alojamento. Dormia todas as noites de trabalho dentro da viatura, foram 22 anos dessa rotina, sem que os superiores considerassem suspeita ou inadequada a conduta, afinal estava casada e tinha uma filha, estava protegida por uma lógica na qual

[...] el matrimonio fuerza, al menos lógicamente, el reconocimiento universal: todos deben dejarte entrar por la puerta del hospital, todos deben respetar tu derecho al luto, todos deben asumir tu derecho natural a un hijo, todos considerarán tu relación como si estuviera elevada a la eternidad. ${ }^{12}$

Segundo Josefina Fernández, ${ }^{13}$ a heterossexualidade opera como o princípio ordenador da sexualidade e, nessa perspectiva, a identidade sexual existiria apenas atrelada ao gênero e à fisiologia no paradigma ocidental de gênero. Lida através dessa matriz, Carolina foi reconhecida por muito tempo como "alguém de respeito": "Eles pensavam que eu era evangélica, por isso era tão reservada. Alguns vinham sempre me pedir opiniões, conselhos sobre sua vida particular e familiar, me consideravam como alguém de bem". ${ }^{14}$

${ }^{10}$ Anotações do Caderno de Campo, Brasília, maio de 2007.

${ }^{11}$ BUTLER, 2004, p. 30.

12 BUTLER, 2006b, p. 162

13 Josefina FERNÁNDEZ, 2004.

${ }^{14}$ Anotações do Caderno de Campo, Brasília, maio de 2007. 


\section{Do armário para a reserva: a fragilidade das normas}

Permanecemos no estacionamento, Carolina revia seu lugar de trabalho, mostravame cada um dos equipamentos, explicava sobre um ofício que se orgulhava de executar. A experiência como militar aproxima Carolina de Christine Jorgensen, integrante do exército estadunidense durante a $2^{a}$ Guerra Mundial que, em 1952, foi submetida à cirurgia de transgenitalização na Dinamarca, sendo reconhecida como a primeira (transexual) a realizar o procedimento no mundo. ${ }^{15}$ Diferentemente de Christine, Carolina não seguiu carreira no show business e tampouco escolheu deixar o serviço de militar.

Ela desempenhou uma carreira considerada exemplar. Até a data de sua aposentadoria por invalidez, foi reconhecida como competente. ${ }^{16} \mathrm{O}$ diagnóstico de transexualismo marcou o final da carreira militar de Carolina, conforme parecer emitido por junta médica oficial através da perícia realizada em fevereiro de 2000 que a considerava "INCAPAZ DEFINITIVAMENTE PARA O SERVIÇO MILITAR". ${ }^{17}$ O conjunto de negativas apresentadas no referido laudo diz, ou supõe dizer, tudo que Carolina não é e também tudo que pode exercer no "mundo civil". O que o texto não explica é o fator que a tornou incapaz para o serviço militar.

Ao examinar as deliberações do exército estadunidense sobre a homossexualidade, Judith Butler ${ }^{18}$ colabora para a compreensão dessa questão, apontando para o acesso a uma cidadania diferenciada para aqueles que estão na condição de militares. Percepção que parece ser compartilhada pelos militares brasileiros durante o período em que pude acompanhar o desenrolar do processo judicial, ainda tramitando, em que Carolina reivindica o retorno ao trabalho e, posteriormente, as suas incansáveis peregrinações pelos órgãos responsáveis pela emissão do documento de identificação militar. A autorização judicial para alteração do nome e do sexo no assento civil imediatamente provocou um incômodo entre os militares. A sentença judicial parecia não ter eficácia junto a esse universo. A concessão da nova identidade militar de Carolina foi marcada por entraves, por solicitação constante de novos documentos e reencaminhamentos para diferentes órgãos. Todos os procedimentos pareciam orquestrados para provocar a desistência.

A possibilidade de trânsito, em termos de gênero, é ameaçadora. A posição do exército estadunidense mostra os mecanismos através dos quais a afirmação da homossexualidade passa a ser considerada um perigo por contaminar a masculinidade, transformando-se em uma conduta ofensiva. ${ }^{19}$ Nesse contexto - compartilhando com Judith Butler de que a regulação implícita do gênero tem lugar na regulação explícita da sexualidade ${ }^{20}$-, a transexualidade torna-se impensável na medida em que os militares não parecem distinguir homossexualidade e transexualidade, o que contribui para compreender o destaque à palavra "definitivamente", expressa no parecer do perito.

A visibilidade da transexualidade de Carolina sinaliza o lugar abjeto que ela passou a ocupar quando desestabilizou as normas do gênero, materializando no corpo as ideias de que a biologia não aprisiona o gênero, que gênero está deslocado do sexo e que a reprodução não sustenta a heterossexualidade. Enfim, essa visibilidade tornou-se ameaçadora ao evidenciar que as normas militares são insuficientes para a produção de

\footnotetext{
15 Joanne MEYEROWITZ, 2004.

${ }^{16}$ Carolina preserva em uma caixa, separadamente, os boletins em que foram publicados os elogios sobre seu desempenho.

${ }^{17}$ Anexo do Processo de J.C.S., grifos do autor.

18 BUTLER, 2004.

19 BUTLER, 2004, p. 185-200.

${ }^{20}$ BUTLER, 2006a, p. 84.
} 
um cidadão militar masculino. Carolina ainda sonha com o dia em que vestirá a farda militar feminina.

\section{A recusa de um script}

Em outro texto, ${ }^{21}$ aponto que muito antes que a temática das transexualidades adentrasse as preocupações das ciências humanas no Brasil, ou mesmo a legitimação da ação da medicina em 1997, a cirurgia de transgenitalização produzia dissensos entre as travestis e transexuais, apontando diferenças em seus universos de sociabilidade. No entanto, não parecia se constituir em uma fronteira identitária. ${ }^{22}$ Para a autora, o termo "transexual" parecia ser utilizado por pesquisadores para adjetivar a cirurgia, e não as pessoas. Ao denominarem de operação transexual ou cirurgia transexual, eles pareciam antecipar o momento posterior em que a cirurgia passaria a operar na construção de uma identidade (transexual) que viria a ser desestabilizada pela recusa de Rita. A sua desistência em se submeter à cirurgia provocou nas pessoas que acompanhei diferentes atitudes ancoradas no diagnóstico: todos pareciam questionar se Rita seria mesmo transexual.

O desejo manifesto pela cirurgia parece ser o marco divisor entre as categorias travestis e transexuais e não apenas para o saber autorizado da medicina ou subjacente aos trabalhos contemporâneos como o de Larissa Pelúcio, nos quais a pesquisadora identificou que, entre as travestis, a cirurgia aparece tangenciando a definição de transexuais. ${ }^{23}$

Um definidor explicitamente colocado por Tassiana, quando me diz, referindo-se possivelmente à recusa de Rita: "uma mulher transexual que não deseja a cirurgia? Impossível, uma transexual só fica sem a cirurgia enquanto não está ao alcance dela, depois que está perto, não, não, ela não desiste. Desconfio dessas transexuais assim....". ${ }^{24}$ Essa desconfiança surge compartilhada mesmo pelas pessoas que estão inseridas nos movimentos sociais. A definição de transexual acionada por Clarissa, que pensa a transexualidade do lugar de psicóloga e mulher (transexual), passa pelo marcador da cirurgia:

Você pode se reconhecer como mulher, pode reivindicar que é mulher, mas dizer que é uma mulher (transexual) não. Pela minha vivência transexual, eu posso dizer que não seria, porque tem uma queixa. Uma queixa na transexualidade comum é "minha prática sexual é horrorosa, porque eu não estou bem com meu corpo, não sou completa". [Na transexualidade] tem um mal estar em relação à genitália. Quem se sente mulher tendo seu pênis, não precisa se dizer transexual, pode ser... Dizer outro termo. ${ }^{25}$

Nesse momento, recuperar a recusa de Rita é uma tentativa de visibilizar as fraturas existentes e algumas interpretações possíveis.

Uma semana antes da cirurgia, eu não conseguia dormir... Sabe quando cai a ficha? Não é para mim [a cirurgia], até esse momento eu não tinha nenhuma dúvida, eu tive um ataque de pânico, estava usando medicamento para dormir. Eu não estava dando conta, o que resolveu mesmo foi abrir mão naquele momento da cirurgia. Isso não significa que é uma decisão definitiva, talvez em outro momento de minha

\footnotetext{
${ }^{21}$ Flávia do Bonsucesso TEIXEIRA, 2009.

22 TEIXEIRA, 2009, p. 168.

${ }^{23}$ Larissa PELÚCIO, 2009, p. 44.

${ }^{24}$ Tassiana, entrevista pessoal, Brasília, outubro de 2007

${ }^{25}$ Clarissa, entrevista pessoal, Brasília, fevereiro de 2008.
} 
vida, mas se você me perguntar sobre minha vida, aos 8 anos de idade eu não imaginava que estaria vivendo como estou hoje. ${ }^{26}$

Acompanhei Rita por um percurso significativo entre o Programa de Transgenitalização do Pró-Vida, o ingresso no grupo do HUB, sua rápida passagem pelo movimento social, a mudança para São Paulo e seu retorno para Brasília, o ingresso no serviço público através de concurso. Essa seria minha primeira visita ao seu apartamento, após a recusa da cirurgia. Ela acabara de chegar do trabalho e suas roupas, de cores sóbrias, foram acomodadas numa cadeira próxima à varanda. A discrição de suas roupas são elementos constitutivos de sua subjetividade: "Eu sou discreta, gosto de ser sóbria assim como minhas roupas, não gosto de brilho e purpurina". O cumprimento de nossos cabelos foi o identificador acionado por ela para dizer do tempo transcorrido desde o nosso último encontro. As roupas, os cabelos, as unhas, sempre o corpo esteve em questão na relação entre a pesquisadora e as entrevistadas; situação já vivida também por Juliana Jayme: "o corpo sempre veio à tona e como pertencente à sua própria formulação de sujeito, à maneira como eles se colocam frente ao outro, frente àqueles que se identificam com eles, enfim à própria sociedade". ${ }^{27}$

Rita sempre se portou como uma interlocutora atenta, a formação em Biologia e o mestrado ainda que incompleto na área de genética conferiam a ela um lugar diferenciado no grupo. O deslocamento das demarcações identitárias, num primeiro momento, expressas na advertência - "você deve observar bem, transexuais são muito diferentes das travestis" 28 -, foi se borrando ao longo desse processo para uma posição que reconhece a fluidez, o intercâmbio e a provisoriedade das identidades e dos corpos: "Inicialmente eu não sabia o que era, depois vivi até os vinte e poucos anos como homossexual e percebi que também não dava conta, resumindo eu estou num momento da minha vida que não acredito em identidade". ${ }^{29}$

Reconhecer o caráter incerto e mutável das identidades significa minar o sistema normativo binário baseado no dimorfismo sexual, certeza que até então cercava o universo de Rita. A tese da Tatiana Lionço estava entre os livros dispostos na estante próxima à mesa, não parecia ter sido colocada ali propositalmente em função de minha visita, pois outros livros empilhados próximos dificultavam a identificação dos títulos, que, no entanto, me eram familiares, e, pelas capas e cores, encontrei também o exemplar do livro de Berenice Bento de 2005. As leituras e a experiência vivida contribuíram para o giro das suas preocupações:

Eu tinha algumas certezas: primeiro eu sempre tive problemas com meu corpo, eu achava disforme, essa é a imagem. A minha identificação com o feminino que foi sempre recalcada por motivos externos, em alguma medida eu tive que construir alguma masculinidade. E o desejo afetivo inicialmente e posteriormente sexual por homens. São os fatos concretos que eu tenho, agora como negociei com isso comigo mesmo foi variável ao longo da vida. Eu estou num momento de minha vida que assim, quando aconteceu de eu desistir da cirurgia, eu resolvi que não me importa os códigos que as pessoas vão usar. Eu vou passar a vida inteira com pessoas olhando para mim e dizendo: é um veado vestido de mulher; é um homossexual vestido de mulher; é um homem vestido de mulher; é uma travesti fina; é uma transexual vestida de travesti; é uma travesti que se pensa transexual, os olhares serão múltiplos. Minha experiência está para além disso. É plural. Não me interessa mais qual a categoria que as pessoas me colocam.

${ }^{26}$ Rita, entrevista pessoal, Brasília, dezembro de 2006

27 JAYME, 1999, p. 16.

${ }^{28}$ Anotações do Caderno de Campo, Brasília, Promotoria Pública, dezembro de 2004

${ }^{29}$ Rita, entrevista pessoal, Brasília, outubro de 2007

${ }^{30}$ Rita, entrevista pessoal, Brasília, outubro de 2007. 
As suas entrevistas anteriores foram marcadas pela preocupação com a origem da transexualidade. O discurso agora oferece tonalidades diferentes nesse momento em que as suas vivências possibilitaram perceber que a sedução da origem não seria capaz de conferir significado aos conflitos e nem mesmo ajudar a resolvê-los. Essa "reviravolta" me conduz aos questionamentos de Lewotin sobre a preocupação dos pesquisadores a respeito da origem biológica da sexualidade: "Mesmo que descubram uma causa biológica [...] O que eu vou fazer com isso?". ${ }^{31}$

\title{
A natureza da gente não cabe em nenhuma certeza ${ }^{32}$
}

Neil é membro da Associação da Parada do Orgulho GLBT de São Paulo (APOGLBTSP) e relata sua história num entrecruzar de lutas individuais que se somam aos movimentos coletivos, parece materializar o argumento abaixo.

\begin{abstract}
[...] aceitar a categorização masculino/feminino a partir da construção de um sexo ou da patologização de sua condição pelas pessoas transexuais, coloca-nos diante de um dilema que não pode ser resolvido no plano do indivíduo. O que faz compreensível o argumento butleriano de que é necessária capacidade crítica para reagir a essas mesmas normas. O que só é alcançável de forma coletiva, ou seja, não serão sujeitos individuais que modificarão a ordem, e sim grupos organizados que busquem articular uma alternativa ao que existe [...].
\end{abstract}

Estar para além das identidades é, também, sua reivindicação. Ainda que ele não tenha se inscrito no Programa de Transgenitalização nem mesmo tenha uma relação direta com os sujeitos com os quais iniciei a pesquisa, a inclusão de sua experiência se justifica porque desestabiliza a experiência da reprodução biológica e a negação da maternidade como destino do sujeito. ${ }^{34}$

"Tudo correu de forma tranqüila e nasceu uma linda menina". ${ }^{35}$ Essa poderia ser uma frase compartilhada por muitos casais ao final de uma gravidez. No entanto, eu desconfiava de que tivesse sido tão tranquilo assim. Vagina, útero, ovários, trompas e uma gestação, as coisas não poderiam ser assim tão "abstratas". Neil tem uma filha de 14 anos, gestada numa relação que se configurava como lésbica, até mesmo para ele.

A união foi marcada pelo desejo de um filho biológico pelo então casal de mulheres lésbicas, em que, a princípio, a gestação seria da companheira de Neil; a decisão foi de que não recorreriam às técnicas de reprodução assistida por questões financeiras e também por serem solteiras. ${ }^{36} \mathrm{~A}$ impossibilidade de que sua companheira engravidasse fez com que Neil decidisse pela gestação. Um casal de amigos gays foi consultado e um dos parceiros aceitou participar do projeto para o nascimento dessa criança. A participação ${ }^{31}$ Chandler BURR, 1998.

32 João GUIMARÃES ROSA, 1970

${ }^{33}$ Richard MISKOLCl e Larissa PELUCIO, 2006, p. 5.

${ }^{34}$ Até então, apesar de seu consentimento, a utilização de sua história, na tese e agora neste artigo, somente se fez porque fragmentos de sua história de vida tornaram-se públicos através de uma entrevista que foi veiculada em revista destinada ao público gay. A preservação do anonimato dos sujeitos que colaboraram na pesquisa é sempre uma questão espinhosa no nosso campo, principalmente em se tratando de pessoas inseridas em movimentos sociais. Mantenho o recurso da mudança de nome porque cumpro a exigência do Comitê de Ética em Pesquisa (na tese discuti as limitações da Resolução CNS n. 196"96 para normatizar as nossas pesquisas e não vou retomá-las aqui por questão de pertinência da temática).

${ }^{35}$ Neil, entrevista pessoal, São Paulo, junho de 2007.

${ }^{36}$ Discussão presente na reunião preparatória para o Seminário Nacional de Saúde da População GLBT, em 2007, que abordou, entre outras questões, a disponibilização de tecnologias reprodutivas para as lésbicas. Demanda reiterada nas reuniões e nos encontros nacionais subsequentes, garantida na Política Nacional de Saúde Integral de Lésbicas, Gays, Bissexuais, Travestis e Transexuais (2009) e instituída através da Portaria MS n. 2.836, de $1^{\circ}$ de dezembro de 2011 . 
foi interpretada como "doação de sêmen" pelos envolvidos. A ausência posterior do pai genético foi um acordo aceito pelas partes, nenhum pai era pretendido para essa criança. Até então, a ordem estaria garantida, pois, segundo Marilyn Strathern, ${ }^{37}$ a ideia de um filho sem pai não provocaria um sentimento de indignação moral, ao mesmo tempo que o ato sexual e a concepção (presentes nesse caso) não cumpririam apenas uma questão técnica, mas garantiriam a reprodução da "parentalidade como resultado percebido de uma união em que as partes se distinguem pelo gênero". ${ }^{38} \mathrm{O}$ corpo de Neil foi o espaço em que toda essa negociação aconteceu, embaralhando as fronteiras dos arranjos reprodutivos e desestabilizando as normas de gênero.

Observei um silenciamento sobre o corpo dos homens (transexuais) na literatura. Ainda que seja para promover a interdição, apresentando a recusa do pênis como norma ou mesmo a condição de assexuada, as mulheres (transexuais) são materializadas num corpo (mesmo que débil), mas os homens (transexuais) são descritos a partir da impossibilidade do falo (ou da sua construção). O desconhecimento de Neil sobre seu corpo é denunciado: "A minha mulher que conhecia essa coisa de corpo de mulher, como período fértil, eu nunca havia ido ao ginecologista, então fomos ao médico, os quatro. Explicamos a situação". ${ }^{39}$

No deslocamento entre conceber a ideia até o ato de gerar a criança, os corpos novamente ocupam um lugar privilegiado. "Foi uma escolha muito difícil e violenta na minha vida, nunca tinha transado com um homem, muito menos fazer o papel de 'passiva' como uma mulher [...]". Um corpo passivo, a metáfora de um corpo-caixa será construída por Neil para explicar sua gravidez como um período em que o corpo seria um recipiente no qual cresceria o presente para sua esposa. No entanto, esse corpo está em movimento e as alterações no corpo foram sentidas como estranhamento, porque ele não poderia antecipar o processo pelo qual os ductos mamários dilatam e produzem leite, as contrações uterinas, os movimentos do bebê.

Eu nunca li nada durante a gravidez, eu não me interessava. Eu não sabia nada disso [...]. Eu fiquei grávido e foi muito louca a questão da gravidez porque eu me considerava um homem, mesmo na questão lésbica e aquilo foi crescendo [a barriga] e eu tinha que usar roupas que não eram masculinas, assim...

A gravidez como apenas um processo espontâneo e fisiológico também escapa ao controle do Neil e o coloca entre as roupas, o feto e o afeto. "Foi emocionante escutar o coraçãozinho do bebê, eu chorei, foi o único momento que eu me lembre." Conversar com o bebê e acariciar a barriga eram ações realizadas pela esposa. Não foram somente as mudanças do corpo e das roupas durante a gravidez que se apresentavam como desafios para Neil, também as relações sociais, a não aceitação num espaço de sociabilidade que ele transitava sem problemas quando estabelecida a distinção de gênero.

Eu era considerado uma lésbica caminhoneira, ${ }^{40}$ andava entre os homens, conversava coisas de homens, mas sem misturar as coisas, você é aceito se corresponder ao papel de homem, de macho. Muitos amigos se afastaram porque não aceitaram o fato de eu ter me deitado com um homem. Há 15 anos atrás, no interior, isso não era admitido entre as lésbicas. Eles não percebiam como era difícil para mim, manter minha masculinidade, apesar de grávido.

\footnotetext{
37 Marilyn STRATHERN, 1995.

38 STRATHERN, 1995, p. 307.

${ }^{39} \mathrm{O}$ acesso das mulheres lésbicas ao serviço de saúde foi tema recorrente nas discussões que contribuíram para a construção da Política Nacional de Saúde Integral de LGBT (2009); no entanto, as demandas dos homens (transexuais) permaneceu silenciada, caminhando a reboque da discussão do processo transexualizador realizada pelas mulheres (transexuais).

${ }^{40}$ Termo utilizado para dizer de mulheres lésbicas consideradas muito masculinas.
} 
A gravidez era a revelação materializada do intercurso sexual com outro homem, foi a confirmação do ato sexual que deslocou Neil para o polo feminino aos olhos dos amigos. Miguel Vale de Almeida ${ }^{41}$ considera que a masculinidade não é simplesmente a interpretação cultural de um dado natural, sua definição, aquisição e manutenção são internamente constituídas por assimetrias e hierarquias num processo de vigilância e disputa. Nesse espaço instável, Neil deixou de ser considerado pertencente ao masculino quando, numa relação direta, os amigos associaram relação heterossexual|gravidezlfemininolmulher|mãe. Ao problematizar o debate sobre a Síndrome do Nascimento Virgem, Marilyn Strathern ${ }^{42}$ postula que as práticas anticoncepcionais separaram sexo de procriação, as novas tecnologias reprodutivas desvincularam concepção e sexo, mas, efetivamente, as sociedades euroamericanas não separaram procriação das relações de gênero.

Neil entende o parto como o demarcador de uma situação ainda de menor controle.

Veio uma enfermeira e me colocou a [...] do lado. Eu fiquei ali, emocionado sim, o desespero mesmo foi quando me disseram que eu teria que amamentar... Eu fiquei desesperado, mandei chamar minha companheira, amamentar não, meus seios não. Sobre isso não tinha acordo.

Gestar, dar à luz, amamentar e acariciar configuram atividades correlatas a um ideal hegemônico de mulher, através do qual a maternidade constituiria a mãe. Segundo Marilyn Strathern, seria inconcebível, na nossa sociedade, uma criança nascer sem mãe e, observando o estranhamento provocado por Neil, penso que é igualmente inimaginável uma mãe não ser mulher.

Se, para Strathern, a problemática colocada pelos Trobriands seria a ideia de uma maternidade sem sexo, penso que o desafio colocado por Neil poderia apoiar a discussão de uma maternidade sem gênero.

Considero que não seja por acaso que as cirurgias de neocovulvoplastia e neofaloplastia produzam sujeitos estéreis. Observei que, após o início do tratamento hormonal, um dos primeiros procedimentos cirúrgicos a que os homens (transexuais) foram submetidos é a retirada do aparelho reprodutor feminino. Não identifiquei nenhuma orientação explícita sobre esse aspecto, mas encontrei no trabalho de Tereza Vieira pistas para pensar. Comentando o Código Civil holandês, ela analisa que a esterilização é uma condição para a realização da cirurgia: "Isto significa que os testículos, os ovários ou o útero devem ser retirados. Tal alínea visa impedir que as crianças nasçam de pais cujo sexo jurídico é oposto ao sexo biológico". ${ }^{44}$ As condutas médicas, no Brasil, (ainda que não normatizadas) parecem garantir que, reivindicando a posição de homens, os homens (transexuais) não desorganizem ainda mais as normas de sexo e gênero ousando ser mães. ${ }^{45}$

\footnotetext{
${ }^{41}$ Miguel Vale de ALMEIDA, 1996.

42 STRATHERN, 1995

${ }^{43} \mathrm{~A}$ interdição dos seios e o uso do enfaixamento para encobrir as mamas são relatos recorrentes das histórias dos homens (transexuais).

${ }^{44}$ Tereza VIEIRA, 1995, p. 208.

${ }^{45} \mathrm{No}$ decorrer da pesquisa de campo foi divulgada a história de Thomas Beatie grávido, a imagem do homem (transexual), em reportagem da revista The Advocate, em março de 2008 e, posteriormente, replicada em diferentes sites de notícias informa o estranhamento e a "espetacularização" provocada pela nova situação. Outro episódio envolvendo a gravidez de um homem (transexual) foi noticiado no site da UOL, já por ocasião da conclusão da tese em fevereiro de 2009. As imagens disponibilizadas, nos dois casos, guardam semelhanças, ambas enfatizam o crescimento do abdômen e a ausência de mamas em contraposição à presença de caracteres secundários masculinos como barba e distribuição pelosa. Na reportagem, o espanhol Rubén Noé diz estar negociando a publicidade de sua gestação, a exemplo do ocorrido com Thomas Beatie. o que confere a essa gravidez a conotação e fantástica.
} 
Acredito que a medicina e o judiciário, no Brasil, ainda não enfrentaram tamanho deslocamento em que nem mesmo a maternidade (um dos ícones do ser mulher) fosse capaz de subjetivar os homens (transexuais) no feminino.

\section{Compartilhando (in)certezas...}

Dificilmente os militares contemporâneos de Carolina compreenderiam que toda aquela aparente subversão não representaria, inicialmente, o deslizamento entre sexo, gênero e sexualidade, e sim traria no seu avesso a reivindicação da coerência e a afirmação das normas de gênero. No seu caso, a cirurgia de transgenitalização traria a verdade a um corpo que teria sido "enganado" pela natureza, reiterando as formulações medico-jurídicas relativas a uma sexualidade fundada em dois sexos opostos e condutas e comportamentos erguidos sobre a base de uma polaridade biológica.

No entanto, a permanência no campo me impediu de considerar as práticas presentes no cotidiano de Carolina (mesmo a incansável espera|luta pela cirurgia) como simples reproduções das normas de gênero. A sua busca pode ser compreendida como uma das condições para tornar seu corpo inteligível. Argumento que, mesmo na reivindicação da cirurgia, no apelo das normas, a transexualidade possui um potencial desestabilizador. ${ }^{46}$

Essa posição é diferente de atribuir à pessoa (transexual) um caráter naturalmente transgressor. As histórias aqui apresentadas sugerem que a transexualidade pode ser um desafio quando nos distanciamos da explicação reducionista de serem pessoas presas num corpo equivocado e compreendemos que são pessoas que combinam os conceitos de masculino e feminino, experimentando em graus diferenciados o "nomadismo", a hibridação, a contaminação entre o ser homem e o ser mulher. ${ }^{47}$

\section{Referências}

ALMEIDA, Miguel Vale de. "Gênero, masculinidade e poder: revendo um caso do Sul de Portugal". Anuário Antropológico, Rio de Janeiro: Tempo Brasileiro, p. 161-189, 1996.

ANTUNES, Arnaldo; GONÇALVES, Hélder; AZEVEDO, Manuela. "Qualquer". Intérprete: Arnaldo Antunes. In: ARNALDO ANTUNES. Qualquer. Rio de Janeiro: Biscoito Fino, 2006. Faixa 4.

ARFINI, Elisa. "Everybody's Passing. Passing, Crossing e Narrazioni Trans." In: RUSPINI, Elisabetta; INGHILLERI, Marco (Org.). Transessualità e scienze sociali: identità di genere nella postmodernità. Napoli: Liguori, 2008. p. 275-294.

BENTO, Berenice M. A reinvenção do corpo: sexualidade e gênero na experiência transexual. Tese (Doutorado em Sociologia) - Departamento de Sociologia, Universidade de Brasília, Brasília, 2003.

. A reinvenção do corpo: sexualidade e gênero na experiência transexual. Rio de Janeiro: Garamond, 2006.

BURR, Chandler. Criação em separado: como a biologia nos faz homo ou hétero. Tradução de Ary Quintella. Rio de Janeiro: Record, 1998.

BUTLER, Judith. El género en disputa. México: Paidós, 2001.

. La rivendicazione di antígone: la parentela tra la vita e la morte. Tradução de Isabella Negri. Torino: Bollati Boringhieri, 2003. . Lenguaje, poder e identidad. Tradução de Javier Sáez e Beatriz Preciado. Madrid: Editorial Síntesis, 2004.

Cuerpos que importan: sobre los limites materiales y discursivos del "sexo". $1^{a}$ reimp. Buenos Aires: Paidós, 2005.

46 BENTO, 2003, p. 110.

${ }^{47}$ Elisabetta RUSPINI e Marco INGHILLERI, 2008, p. 86. 
Deshacer el gènero. Barcelona: Paidós, 2006a.

Vida precária: el poder del duelo y la violência. Buenos Aires: Paidós, 2006b.

FERNÁNDEZ, Josefina. Cuerpos desobedientes: travestismo e identindad de gênero. Buenos Aires: Edhasa, 2004

GUIMARÃES ROSA, João. Grande sertão: veredas. Rio de Janeiro: José Olympio, 1970.

JAYME, Juliana Gonzaga. Travestis, transformistas, drag-queens, transexuais: personagens e máscaras no cotidiano de Belo Horizonte e Lisboa. Tese (Doutorado em Ciências Sociais) - Programa de Pós-Graduação em Ciências Sociais, Universidade Estadual de Campinas, Campinas, 1999.

LIONÇO, Tatiana. Um olhar sobre a transexualidade a partir da perspectiva da tensionalidade somato-psíquica. Tese (Doutorado em Psicologia) - Programa de PósGraduação em Psicologia, Universidade de Brasília, Brasília, 2006.

MEYEROWITZ, Joanne. How Sex Changed. Cambridge, Massachusetts: Harvard University Press, 2004.

MISKOLCI, Richard; PELÚCIO, Larissa. "Fora do sujeito e fora do lugar: reflexões sobre performatividade a partir de uma etnografia entre travestis". In: 30 ENCONTRO ANUAL DAANPOCS, 2006, Caxambu, MG. Anais... Caxambu, MG, 2006. GT Sexualidade, Corpo e Gênero.

MORISSON, Toni. O olho mais azul. Tradução de Manoel Paulo Ferreira. São Paulo: Companhia das Letras, 2003.

OLIVEIRA, Leandro. Gestos que pesam: performance de gênero e práticas homossexuais em contexto de camadas populares. Dissertação (Mestrado em Saúde Coletiva) - Instituto de Medicina Social, Programa de Pós-Graduação em Saúde Coletiva, Universidade Estadual do Rio de Janeiro, Rio de Janeiro, 2006.

NIQUINHO; RUSSO, Othon. "Há uma história triste". Intérprete: Elis Regina. In: ELIS REGINA. O bem do amor. Rio de Janeiro: CBS, 1963. Faixa 7.

PELÚCIO, Larissa. Abjeção e desejo: uma etnografia travesti sobre o modelo preventivo de aids. São Paulo: Annablume, 2009.

RUSPINI, Elisabetta; INGHILLERI, Marco (Org.). Transessualità e scienze sociali: identità di genere nella postmodernità. Napoli: Liguori, 2008.

STRATHERN, Marylin. "Necessidade de pais, necessidade de mães". Revista Estudos Feministas, v. 3, n. 2, p. 303-329, 1995.

TEIXEIRA, Flavia do Bonsucesso. Vidas que desafiam corpos e sonhos: uma etnografia do construir-se outro no gênero e na sexualidade. Tese (Doutorado em Ciências Sociais) Programa de Doutorado em Ciências Sociais, Universidade Estadual de Campinas, Campinas, 2009.

VIEIRA, Tereza R. Pelo reconhecimento da legalidade do direito à adequação do sexo do transexual. Tese (Doutorado em Direito) - Programa de Pós-Graduação em Direito, Pontifícia Universidade Católica de São Paulo, São Paulo, 1995.

VIVEIROS DE CASTRO, Eduardo. A inconstância da alma selvagem e outros ensaios de Antropologia. São Paulo: Cosac e Naify, 2002.

Stories without a "once upon a time": The (Un)certainties of Transsexuality

Abstract: From fragments of life stories of (transsexual) people, I try to explain the diversity of their livings, unique experiences, ways of making sense of the process of breaking the gender norms and sexuality. I analyze the inadequacy of medical-legal discourse, anchored in an essencialized truth on the sexualized body, to capture the possibilities of experiences in transsexuality. I argue that the destabilizing potential of transsexuality lies in withdrawing from the reductionist view, which considerss transsexuals as misguided people trapped in a body whose intelligibility would depend solely upon reassignment surgery.

Key Words: Transsexuality; Gender; Sexuality; Reassignment.

512 Estudos Feministas, Florianópolis, 20(2): 501-512, maio-agosto/2012 